\title{
Caracterización fenotípica por resistencia a sequía terminal de germoplasma de frijol común ${ }^{1}$
}

\section{Phenotypic characterization of common bean germplasm for resistance to terminal drought}

\author{
Néstor Felipe Chaves-Barrantes², José A. Polanía ${ }^{3}$, Carlos Germán Muñoz-Perea4 ${ }^{4}$ Idupulapati M. Rao ${ }^{3}$, \\ Stephen E. Beebe
}

\begin{abstract}
Resumen
La sequía terminal es una limitante mundial para la producción de frijol y se acentuará por efecto del cambio climático. El objetivo de este estudio fue caracterizar fenotípicamente líneas avanzadas y germoplasma comercial de frijol por su resistencia a sequía terminal. La investigación se realizó durante el 2012 y 2013 en el Centro Internacional de Agricultura Tropical (CIAT), Palmira, Colombia; bajo riego y sequía terminal. Se utilizó un látice 4x4 parcialmente balanceado con cuatro repeticiones. Para lograr la condición de sequía terminal, el riego se suspendió a los 22-23 días después de la siembra. La sequía terminal redujo, en promedio, un 68\% el rendimiento. Las líneas SEN 56, BFS 29, NCB 226 y SER 16, mostraron alto rendimiento en riego (3617-3836 kg/ha) y en sequía terminal (1232-1447 kg/ha), mientras que las líneas RCB 593 y G 40001 mostraron alto rendimiento (>1270 kg/ha) en sequía terminal y similar al de los testigos bajo riego. Las líneas más resistentes mostraron menores índices de susceptibilidad a sequía $(0,88$ - 1,00), aceleración de la madurez (56 - 60 dds), media geométrica superior (1931 - $2311 \mathrm{~kg} / \mathrm{ha}$ ) y mayor número de granos $/ \mathrm{m}^{2}(673$ - 1250). Las líneas más resistentes obtuvieron al menos un 15 y $50 \%$ más de rendimiento en riego y sequía terminal, respectivamente, que EAP 9510-77, testigo comercial para Centroamérica. Además, superaron a otros testigos comerciales como DOR 390 y Bribrí.
\end{abstract}

Palabras clave: índice de cosecha, media geométrica, partición de biomasa, Phaseolus vulgaris L.

\begin{abstract}
Terminal drought is a worldwide constraint to common bean production and its negative effects will be increased by climate change. The objective of this research was to characterize phenotypically advanced lines and commercial cultivars of common bean for their resistance to terminal drought stress. Field trials were conducted during 2012 and 2013 at Centro Internacional de Agricultura Tropical (CIAT), Palmira, Colombia. A 4x4 partially balanced lattice design with four replicates was used and, evaluated under irrigation and terminal drought. To achieve the terminal drought condition, irrigation was suspended at 22-23 days after planting. Terminal drought reduced mean grain yield
\end{abstract}

1 Recibido: 18 de enero, 2017. Aceptado: 3 de abril, 2017. Este trabajo formó parte de la tesis del primer autor para obtener el grado académico de Doctor en Ciencias Agrarias línea de Mejoramiento Genético Vegetal, Universidad Nacional de Colombia, Sede Palmira, Colombia.

2 Universidad de Costa Rica, Estación Experimental Agrícola Fabio Baudrit Moreno, Programa de Leguminosas. Alajuela, Costa Rica. nfchaves@gmail.com

3 Centro Internacional de Agricultura Tropical (CIAT).A.A.6713, Cali, Colombia. j.a.polania@cgiar.org, i.rao@cgiar.org, s.beebe@cgiar.org

4 Universidad Nacional de Colombia, Facultad de Ciencias Agropecuarias, Sede Palmira. A.A. 237, Palmira, Colombia. cgmunozp@unal.edu.co 
by 68\%. Lines SEN 56, BFS 29, NCB 226 and SER 16 showed high grain yield in both irrigated (3617-3836 kg/ ha) and terminal drought (1232-1447 kg/ha) conditions, while RCB 593 and G 40001 showed high grain yield in drought $(>1270 \mathrm{~kg} / \mathrm{ha})$ and similar to checks in irrigated condition. The most resistant lines showed lower drought susceptibility index $(0,88-1,00)$, earlier maturity (56 - $60 \mathrm{dds})$, superior geometric mean (1931 - $2311 \mathrm{~kg} / \mathrm{ha})$, and higher number of grains/m2, (673 - 1250). Drought resistant lines produced at least $15 \%$ and $50 \%$ more grain yield than EAP 9510-77, commercial check for Central America, in irrigated and drought condition, respectively. In addition, they were also superior to other commercial checks such as DOR 390 and Bribri.

Keywords: biomass partitioning, geometric mean, harvest index, Phaseolus vulgaris L.

\section{Introducción}

El frijol común (Phaseolus vulgaris L.) es la leguminosa de grano más importante para el consumo humano a nivel mundial (Broughton et al., 2003), y constituye una de las mayores fuentes de proteína para los habitantes de Latinoamérica y África del Este, en especial para las personas de bajos recursos (Graham y Rinalli, 1997; Beebe et al., 2013). Se cultiva en todo el mundo, en especial en los países en desarrollo de África y América Latina, donde la mayoría de la producción se encuentra en manos de pequeños productores, con sistemas de baja utilización de insumos, por lo que, es un cultivo de gran impacto económico y social (Broughton et al., 2003).

La sequía es una limitante mundial para la producción de frijol común y se estima que afecta entre el 60 y 73\% del área cultivada (White y Singh, 1991a; Wortmann et al., 1998; Beebe et al., 2009); ocasiona pérdidas en rendimiento que varían entre el 41 y 92\% (Terán y Singh, 2002a; 2002b) y es un problema que se agravará por efecto del cambio climático (McClean et al., 2011). Dentro de las áreas de producción de frijol, el este y sur de África, el oeste de Estados Unidos, el noreste de Brasil, las tierras altas del centro y norte de México, y el norte de Centroamérica, son comúnmente afectadas por sequía (Muñoz-Perea et al., 2006; Beebe et al., 2009; 2011; 2013). Además, en México y Centroamérica el problema se acentúa debido al fenómeno de El Niño (Rogers, 1988; Fernández y Ramírez, 1991).

Los efectos y la reducción en el rendimiento de frijol común por causa de la sequía dependen de la frecuencia, duración e intensidad del estrés, así como de la etapa de desarrollo que se vea afectada (Singh, 1995; Muñoz-Perea et al., 2006). Para una alta emergencia y un buen establecimiento del cultivo, se requiere de una adecuada humedad del suelo; durante las etapas tempranas de crecimiento vegetativo el requerimiento hídrico es relativamente bajo, pero luego se incrementa y se vuelve crítico en prefloración y la etapa reproductiva (Muñoz-Perea et al., 2007). Por esta razón, la sequía terminal, que es la más frecuente en las áreas de producción de frijol a nivel mundial, suele tener un efecto negativo más severo sobre el rendimiento (Porch et al., 2009).

En frijol común, el estrés por sequía provoca una reducción en el contenido de clorofila, humedad y el potencial hídrico de los tejidos foliares, lo que ocasiona una menor acumulación de biomasa y menor crecimiento de la planta (Rosales et al., 2004; Polanía et al., 2009; Omae et al., 2012). Durante la etapa reproductiva causa aborto floral y de vainas jóvenes (Muñoz-Perea et al., 2006). Además, afecta negativamente la concentración, partición y fijación del nitrógeno, la absorción de fósforo y la translocación de asimilados, lo que resulta en una reducción del índice de cosecha, el número de vainas y semillas, el peso de la semilla y del rendimiento (Foster et al., 1995; Castellanos et al., 1996; Ramírez-Vallejo y Kelly, 1998; dos-Santos et al., 2004; Rosales-Serna et al., 2004; Nuñez-Barrios et al., 2005; Beebe et al., 2013).

La reducción en el rendimiento del frijol también se incrementa por la interacción con otros tipos de estrés, favorecidos por la sequía, como alta temperatura (Ramírez-Vallejo y Kelly, 1998), el suelo seco que dificulta la 
penetración radical (Passioura, 2002), pudriciones radicales por Fusarium solani f. sp. phaseoli (Burk), Pythium ultimum Trow y Rhizoctonia solani Künh, el tizón cenizo del tallo causado por Macrophomina phaseolina (Tassi) Goid, y plagas como el saltahojas (Empoasca kraemeri Ross and Moore) (Muñoz-Perea et al., 2006; Porch et al., 2009).

Para encontrar fuentes de resistencia a sequía en frijol, se debe considerar el origen evolutivo del cultivo y su domesticación, así como recurrir a genes y caracteres en diferentes grupos genéticos (Beebe, 2012). Dentro de $P$. vulgaris la raza Durango, originaria y domesticada en las zonas semiáridas del centro y norte de México, ha sido una fuente de resistencia a sequía, debido a su alta producción de grano e índice de cosecha en esta condición (Singh et al., 1991; Terán y Singh, 2002a; Beebe et al., 2013). La raza Mesoamérica, de grano pequeño, y originaria de América Central y el sur de México, también representa una fuente de resistencia a sequía, en especial el subgrupo M2 (Beebe et al., 2014). De la combinación de las razas Durango y Mesoamérica, han surgido las líneas más resistentes a sequía y adaptadas a tierras bajas en ambientes tropicales (Frahm, 2004; Beebe et al., 2008 y 2013). Otra fuente de resistencia a sequía son las especies relacionadas del género Phaseolus, entre ellas el frijol tépari (P. acutifolius A. Gray), que pertenece al acervo terciario y que puede ser cruzado con el frijol común con ayuda del rescate de embriones (Freytag y Debouck, 2002; Porch et al., 2013; Beebe et al., 2014). P. acutifolius, originario y domesticado en las zonas semiáridas del norte de México y suroeste de Estados Unidos, presenta altos niveles de resistencia a sequía y temperatura elevada (Muñoz et al., 2004 y 2006; Micheletto et al., 2007; Blair et al., 2012).

La liberación de líneas de frijol resistentes a sequía ha conducido a un mejor entendimiento de la genética del caracter, que presenta efectos aditivos y cuantitativos, y una interacción significativa con el ambiente cuando se mide en términos de rendimiento, el indicador más confiable para su evaluación (Terán y Singh, 2002a; MuñozPerea et al., 2007; Porch et al., 2009). Debido a la alta interacción genotipo por ambiente, es importante realizar la evaluación de germoplasma para resistencia a la sequía en el ambiente meta (Porch et al., 2009). El objetivo del presente estudio fue caracterizar fenotípicamente líneas avanzadas y germoplasma comercial de frijol común por su resistencia a sequía terminal.

\section{Materiales y métodos}

Para caracterizar fenotípicamente, y conocer su grado de resistencia a la sequía terminal, once líneas y cuatro variedades de frijol común, más una accesión de frijol tépari, se sembraron en condición de riego y sequía terminal en los campos experimentales del Centro Internacional de Agricultura Tropical (CIAT) en Palmira, Colombia (N03 $\left.30^{\prime}, \mathrm{W}^{\circ} 6^{\circ} 21^{\prime}, 965 \mathrm{msnm}\right)$. Los ensayos en condición de riego se sembraron el 10 de agosto del 2012 y el 18 de julio del 2013, mientras que los de sequía terminal el 03 de agosto del 2012 y el 15 de julio del 2013. El CIAT en Palmira, presenta un promedio anual de precipitación de $896 \mathrm{~mm}, 74 \%$ de humedad relativa y $1834 \mathrm{~mm}$ de evapotranspiración potencial; a su vez, una temperatura media anual de $24,3{ }^{\circ} \mathrm{C}$, con una máxima promedio de $28,4{ }^{\circ} \mathrm{C}$ y mínima promedio de $18,8^{\circ} \mathrm{C}$. Los suelos son de tipo Molisol, fino limoso, mixto, isohipertérmicos Aquic Hapludoll, con un pH de 7,5 (Beebe et al., 2008).

Los genotipos evaluados pertenecen al acervo genético mesoamericano, excepto Calima (andino) y la accesión G 40001 (P. acutifolius). Incluyen líneas élites y avanzadas para sequía, bajo fósforo, resistencia a aluminio, y los testigos comerciales DOR 390, Bribrí, EAP 9510-77, Calima y Carioca (G 4017) (Cuadro 1). DOR 390 fue liberada como la variedad "Negro Tacaná" en México en 1994, "ICTA Costeña" en Guatemala en 1995, "Tomeguín 93" en Cuba en 1996, e "INTA Nueva Guinea" en Nicaragua en 2002 (Rosas et al., 2004a). Bribrí es una de las mejores variedades rojas en Costa Rica y fue el cultivar con mayor área sembrada en el 2004 (Hernández et al., 2001; Rosas et al., 2003; Hernández y Elizondo, 2006); mientras que EAP 9510-77 es una de las variedades rojas comerciales más sembradas en Centroamérica y conocida como Amadeus 77 en Honduras, Cabécar en Costa Rica, CENTA San Andrés en El Salvador e INTA Rojo en Nicaragua (Rosas et al., 2004a y 2004b). Calima es una variedad que 
Cuadro 1. Características de los genotipos de frijol común evaluados bajo riego y sequía terminal. Centro Internacional de Agricultura Tropical (CIAT), Palmira, Colombia. 2012-2013.

Table 1. Characteristics of evaluated genotypes under irrigation and terminal drought conditions. Centro Internacional de Agricultura Tropical (CIAT), Palmira, Colombia. 2012-2013.

\begin{tabular}{|c|c|c|c|c|c|c|}
\hline Genotipo & Pedigrí & Origen $^{1}$ & $\mathbf{H}^{2}$ & $\mathrm{C}^{3}$ & $\mathbf{T}^{4}$ & BCMV $^{5}$ \\
\hline ALB 74 & SER $16 \times\left(\right.$ SER $16 \times$ G 35346-3Q)F $F_{1}$ & CIAT, Colombia & 2B & $\mathrm{Rj}$ & M & $I$ \\
\hline BFS 29 & $\left(\right.$ SER $48 \times$ RCB 234)F $F_{1} \times($ SER $118 \times$ NCB 226$) F_{1}$ & CIAT, Colombia & $2 \mathrm{~A}$ & $\mathrm{Rj}$ & $\mathrm{P}$ & $b c-3$ \\
\hline DOR 390 & (DOR 364 x G 18521) x (DOR 365 x LM 30630) & CIAT, Colombia & $2 \mathrm{~A}$ & $\mathrm{Ne}$ & $\mathrm{P}$ & \\
\hline INB 841 & INB 108 x INB 605 & CIAT, Colombia & $2 \mathrm{~A}$ & $\mathrm{Ca} \mathrm{jd}$ & $\mathrm{P}$ & $I$ \\
\hline NCB 226 & $(\mathrm{SXB} 123 \times$ DOR 677$) \mathrm{F}_{1} \times \mathrm{SEN} 34$ & CIAT, Colombia & 2B & $\mathrm{Ne}$ & M & $b c-3$ \\
\hline RCB 593 & (NCB $228 \times$ RCB 224)F $F_{1}$ x SXB 244 & CIAT, Colombia & $2 \mathrm{~B}$ & $\mathrm{Rj}$ & M & $b c-3$ \\
\hline SCR 9 & SER 176 x RCB 591 & CIAT, Colombia & $2 \mathrm{~A}$ & $\mathrm{Sd}$ & M & $b c-3$ \\
\hline SEN 56 & $(\mathrm{SXB} 123 \times$ DOR 677$) \mathrm{F}_{1} \times \mathrm{SEN} 34$ & CIAT, Colombia & $2 \mathrm{~A}$ & $\mathrm{Ne}$ & M & $I$ \\
\hline SER 16 & $\begin{array}{l}\text { (RAB } 651 \times \text { TIO CANELA 75)F } F_{1} \text { x (RAB } 608 \text { x SEA } \\
\text { 15) } \mathrm{F}_{1}\end{array}$ & CIAT, Colombia & $2 \mathrm{~A}$ & $\mathrm{Rj}$ & $\mathrm{P}$ & $I$ \\
\hline SER 118 & (SXB $123 \times$ EAP 9503-32B)F $F_{1} \times$ RCB 137 & CIAT, Colombia & $2 \mathrm{~A}$ & $\mathrm{Rj}$ & M & $I$ \\
\hline SXB 412 & $($ A $686 \times$ A 774$) \mathrm{F}_{1} \times(\mathrm{NXB} 80 \times$ SEA 15$) \mathrm{F}_{1}$ & CIAT, Colombia & $2 \mathrm{~B}$ & $\mathrm{Cr}$ & M & $I$ \\
\hline EAP 9510-77 & TÍO CANELA 75 x DICTA 105 & EAP, Honduras & $2 \mathrm{~A}$ & $\mathrm{Rj}$ & $\mathrm{P}$ & $I$ \\
\hline Bribrí & (RAB 310/XAN 155) x (DOR 391/POMPADOUR G) & EAP, Honduras & $2 \mathrm{~A}$ & $\mathrm{Rj}$ & $\mathrm{P}$ & \\
\hline Calima & $\begin{array}{l}\text { (Perú } 5 \text { x Ant. 10) x (Ant. } 19 \text { x Ant. 10) donde Ant. } 10 \\
=\text { Algarrobo; Ant. } 19 \text { = Estrada Rosado }\end{array}$ & ICA, Colombia & 1 & $\mathrm{Rj} \mathrm{mt}$ & $\mathrm{G}$ & \\
\hline Carioca & & Brasil & $3 \mathrm{~B}$ & Cr rd & M & \\
\hline G 40001 & & Veracruz, México & 2 & $\mathrm{~B} 1$ & $\mathrm{P}$ & \\
\hline
\end{tabular}

${ }^{1}$ CIAT: Centro Internacional de Agricultura Tropical; EAP: Escuela Agrícola Panamericana; ICA: Instituto Colombiano Agropecuario.

${ }^{2} \mathrm{H}$ : hábito de crecimiento / $\mathrm{H}$ : growth habit.

${ }^{3} \mathrm{C}$ : color de grano; $\mathrm{Rj}$ : rojo; Ne: negro; Ca jd: café jaspeado; Sd: rojo seda; Cr: crema; $\mathrm{Cr}$ rd: crema rosado; $\mathrm{Rj}$ mt: rojo moteado; $\mathrm{Bl}$ : blanco / C: seed color; Rj: red; Ne: black; Ca jd: mottled brown; Sd: red "seda"; Cr: cream; Cr rd: cream pink; Rj mt: mottled red; Bl: white. ${ }^{4}$ T: tamaño de grano; P: pequeño; M: mediano; G: grande / T: seed size; P: small; M: medium; G: large.

${ }^{5}$ BCMV: virus del mosaico común del frijol; I: gen de resistencia dominante; $b c-3$ : gen de resistencia recesivo / BCMV: bean common mosaic virus; $I$ : resistance dominant gene; $b c-3$ : resistance recesive gene.

fue desarrollada y liberada en 1966 por el Instituto Agropecuario Colombiano (ICA), muy popular en Colombia y utilizada en Panamá, Mozambique, Tanzania y Burundi (Voysest, 2000). Carioca es una variedad brasileña del Instituto Agronómico de Campinas de São Paulo, recibida en 1966 desde Palmital, São Paulo y vigente hasta la fecha. Su origen se desconoce, aunque se especula que pudo provenir de México, donde hay materiales muy parecidos a este (Voysest, 2000).

Para caracterizar los genotipos de frijol se utilizó un diseño de látice 4x4 parcialmente balanceado con cuatro repeticiones, evaluado bajo dos condiciones, riego (R) y sequía terminal (ST). Cada repetición contó con cuatro hileras de 3,72 $\mathrm{m}$ de largo espaciadas $0,60 \mathrm{~m}$ y con una densidad de quince semillas por metro lineal. Para las dos condiciones, se utilizaron lotes separados y aislados. Los riegos se realizaron por gravedad, se estimó una lámina de $35 \mathrm{~mm}$ en cada uno, y su frecuencia se ajustó según las precipitaciones que ocurrieron. El ensayo en condición de riego recibió seis irrigaciones ( $210 \mathrm{~mm}$ ), tanto en el 2012 como en el 2013, mientras que el ensayo en condición de sequía terminal recibió tres riegos $(105 \mathrm{~mm})$ en cada año. En ambas condiciones el primer riego se realizó en pre-siembra (cinco días antes), mientras que en sequía terminal el último riego se realizó justo antes del período de floración, entre los 22 y 23 días después de la siembra (dds). 
Durante el período del ensayo se registraron las condiciones climáticas imperantes con la estación meteorológica del CIAT e instrumentos colocados in situ. Se midieron la precipitación, la temperatura máxima y mínima, la humedad relativa y la evapotranspiración.

Se registró también la fenología de las plantas de frijol. Los días a floración (DAF) y a madurez fisiológica (DAM) se tomaron cuando el 50\% de las plantas de cada genotipo presentaron una flor o una vaina madura, respectivamente. Los días a mitad de llenado de vainas se tomaron cuando las hojas de las plantas empezaron a tornarse amarillas, ya no habían flores y las semillas se marcaban en las vainas (estaban claramente definidas).

El rendimiento se estimó con una parcela útil de 3,00 m lineales de cada una de las dos hileras centrales (3,60 $\mathrm{m}^{2}$ ), por lo que, se dejó sin cosechar 0,36 m de ambos lados de cada hilera, y las hileras externas para evitar el efecto borde. Sobre las hileras externas de cada repetición se realizaron los muestreos destructivos. Las plantas cosechadas se trillaron mecánicamente, el grano se limpió con una máquina de venteo, se secó al sol, y se determinó el rendimiento en $\mathrm{kg} / \mathrm{ha}$ al $14 \%$ de humedad. El peso de 100 semillas (g) fue cuantificado con ayuda de una balanza analítica, a partir de una muestra homogenizada tomada al azar.

En la etapa de mitad de llenado de vainas se midieron variables fisiológicas como el contenido de clorofila, la eficiencia del fotosistema II, la conductancia estomática y la depresión de la temperatura del dosel con respecto al ambiente (Beebe et al., 2013). El contenido de clorofila se midió con un medidor de clorofila manual no destructivo, la conductancia estomática con un porómetro portátil y la eficiencia del fotosistema II (QY) con un fluorómetro portátil de QY; estas variables se midieron en la misma hoja, la más joven completamente expandida de tres plantas por repetición. La depresión de la temperatura del dosel con respecto al ambiente se midió con un termómetro infrarrojo. Para ello, se sostuvo el termómetro infrarrojo a $50 \mathrm{~cm}$ sobre la superficie del cultivo en un ángulo de $45^{\circ}$ y se realizó la medición. Esta medida se hizo sobre un surco por repetición, entre las 11 am y 3 pm, en días despejados y sin viento.

La biomasa de la parte aérea de la planta se determinó en la etapa de mitad de llenado de vainas y al momento de cosecha. Para ello, se cosecharon $0,5 \mathrm{~m}$ lineales $\left(0,3 \mathrm{~m}^{2}\right)$, por repetición, de uno de los surcos laterales de cada genotipo. Las plantas se cortaron a nivel del suelo y se separaron en componentes: tallo, hojas (sin peciolo), vainas y granos. Con ayuda de un medidor de área foliar se determinó el índice de área foliar (IAF) en la etapa de mitad de llenado de vainas. Luego, cada componente se puso a secar por separado en un horno a $60{ }^{\circ} \mathrm{C}$ por dos días para cuantificar la producción de materia seca.

Con los datos de biomasa a mitad de llenado de vainas y a cosecha, y de rendimiento, se procedió a calcular los índices de adaptación a déficit hídrico y de distribución de biomasa para cada genotipo, acorde con lo indicado por Fischer y Maurer (1978), Terán y Singh (2002a) y Beebe et al. (2013). Se calcularon los índices de: cosecha (IC), cosecha de vainas (ICV), partición a vainas (IPV), llenado de granos (ILLG), susceptibilidad a sequía (ISS) e intensidad de sequía (IIS), para cada época de siembra. También se calculó el porcentaje de reducción (PR) del rendimiento debido al estrés por sequía y la media geométrica (MG) para cada genotipo. La reducción porcentual para biomasa y del número de granos $/ \mathrm{m}^{2}$ debida a la sequía, se calculó adaptando la fórmula de PR para cada variable.

$$
\begin{aligned}
& I C(\%)=(S b h / S h b m) \times 100 \\
& I C V(\%)=(S b h / P b h) \times 100 \\
& I P V(\%)=(P b h / S h b m) \times 100 \\
& I L L G(\%)=(\text { Sds/Sns }) \times 100
\end{aligned}
$$

$$
\begin{aligned}
& I I S=1-(X d s / X n s) \\
& I S S=[1-(Y d s / Y n s)] / I I S \\
& P R=100-[(Y d s / Y n s) * 100] \\
& M G=(Y n s \times Y d s)^{1 / 2}
\end{aligned}
$$

Donde:

Sbh: peso seco de la biomasa de semillas a cosecha.

Shbm: peso seco de la biomasa de la parte aérea a mitad de llenado de vainas.

Stbh: peso seco de la biomasa del tallo a cosecha. 
$P b h$ : peso seco de la biomasa de vainas a cosecha.

Sds: peso seco de 100 semillas en sequía terminal.

Sns: peso seco de 100 semillas en riego.

$X d s$ : promedio de rendimiento de todos los genotipos en sequía terminal.

Xns: promedio de rendimiento de todos los genotipos en riego.

$Y d s$ : rendimiento de un genotipo dado en sequía terminal.

Yns: rendimiento de un genotipo dado en riego.

Para analizar los datos se empleó un modelo mixto, donde los años y bloques (repeticiones) fueron considerados efectos aleatorios, y el ambiente (riego o sequía terminal) y los genotipos, efectos fijos. Los datos para cada año fueron analizados separadamente y la homogeneidad de la varianza del error fue comprobada de acuerdo con Bartlett (1947), antes de realizar el análisis combinado. Mediante correlación simple se determinó cuáles de las variables explicaban mejor la adaptación de las líneas a condiciones de sequía. Para el análisis, se emplearon los procedimientos PROC MIXED y PROC CORR del programa estadístico SAS (versión 9.1.3).

\section{Resultados}

Las condiciones climáticas prevalecientes para el ambiente de riego y de sequía terminal fueron similares en los dos años de estudio (Cuadro 2); con escasa precipitación (entre 70 y 129 mm) y, entre 36 y 40 días con alta

Cuadro 2. Condiciones climáticas durante los ensayos, número de riegos y cantidad de agua suministrada a dieciséis genotipos de frijol evaluados bajo riego (R) y sequía terminal (ST). Centro Internacional de Agricultura Tropical (CIAT), Palmira, Colombia. 2012-2013.

Table 2. Climate conditions during trials, number of irrigation events, and amount of supplied water to sixteen bean genotypes evaluated under irrigation (R) and terminal drought (ST). Centro Internacional de Agricultura Tropical (CIAT), Palmira, Colombia. 2012-2013.

\begin{tabular}{lcccc}
\hline & \multicolumn{2}{c}{$\mathbf{2 0 1 2}^{*}$} & \multicolumn{2}{c}{$\mathbf{2 0 1 3}^{* *}$} \\
\cline { 2 - 5 } Variable & $\mathbf{R}$ & $\mathbf{S T}$ & $\mathbf{R}$ & $\mathbf{S T}$ \\
\hline Número de riegos & 6 & 3 & 6 & 3 \\
Cantidad de agua suministrada $(\mathrm{mm})$ & 210 & 105 & 210 & 105 \\
Precipitación $(\mathrm{mm})$ & 129 & 70 & 72 & 75 \\
Temperatura máxima promedio $\left({ }^{\circ} \mathrm{C}\right)$ & 30,7 & 31,0 & 30,2 & 30,1 \\
Temperatura mínima promedio $\left({ }^{\circ} \mathrm{C}\right)$ & 19,0 & 19,0 & 19,1 & 19,1 \\
Humedad relativa promedio $(\%)$ & 69 & 67 & 71 & 71 \\
Evapotranspiración total $(\mathrm{mm})$ & 367 & 351 & 339 & 319 \\
Evapotranspiración promedio diaria $(\mathrm{mm} / \mathrm{d})$ & 5,2 & 5,4 & 5,0 & 4,8 \\
Temperatura máxima alcanzada $\left({ }^{\circ} \mathrm{C}\right)$ & 33,9 & 33,9 & 34,1 & 32,7 \\
Temperatura mínima alcanzada $\left({ }^{\circ} \mathrm{C}\right)$ & 21,2 & 21,2 & 21,3 & 21,3 \\
No. de días con temperatura máxima $>32{ }^{\circ} \mathrm{C}$ & 12 & 15 & 9 & 5 \\
No. de días con temperatura mínima $>20{ }^{\circ} \mathrm{C}$ & 12 & 12 & 12 & 12 \\
No. días con evapotranspiración $>5 \mathrm{~mm} / \mathrm{d}$ & 37 & 39 & 40 & 36 \\
\hline
\end{tabular}

* Ciclo de cultivo en riego: Ago. 10 - Oct. 18 y sequía terminal: Ago. $03^{\text {rd }}$ - Oct. 06 / Crop season: under irrigation: Aug. $10^{\text {th }}-$ Oct. $18^{\text {th }}$ and terminal drought: Aug. $03^{\text {rd }}-$ Oct. $06^{\text {th }}$.

** Ciclo de cultivo en riego: Jul. 18 - Set. 23 y sequía terminal: Jul. 15 - Set. 19 / Crop season: under irrigation: Jul. $18^{\text {th }}-$ Sep. $23^{\text {rd }}$ and terminal drought: Jul. $15^{\text {th }}-$ Sep. $19^{\text {th }}$. 
evapotranspiración (>5 mm/d). La distribución de las lluvias y manejo del riego durante el ciclo de cultivo (Figura 1), indicaron que una vez alcanzada la etapa de floración, 30 dds en las líneas más precoces, se tuvo una condición de sequía terminal en el ambiente con estrés. Al respecto, el impacto de la sequía terminal experimentada durante la realización del ensayo, medido a través del IIS, fue similar en los dos años de estudio, 0,66 en el 2012 y 0,70 en el 2013.
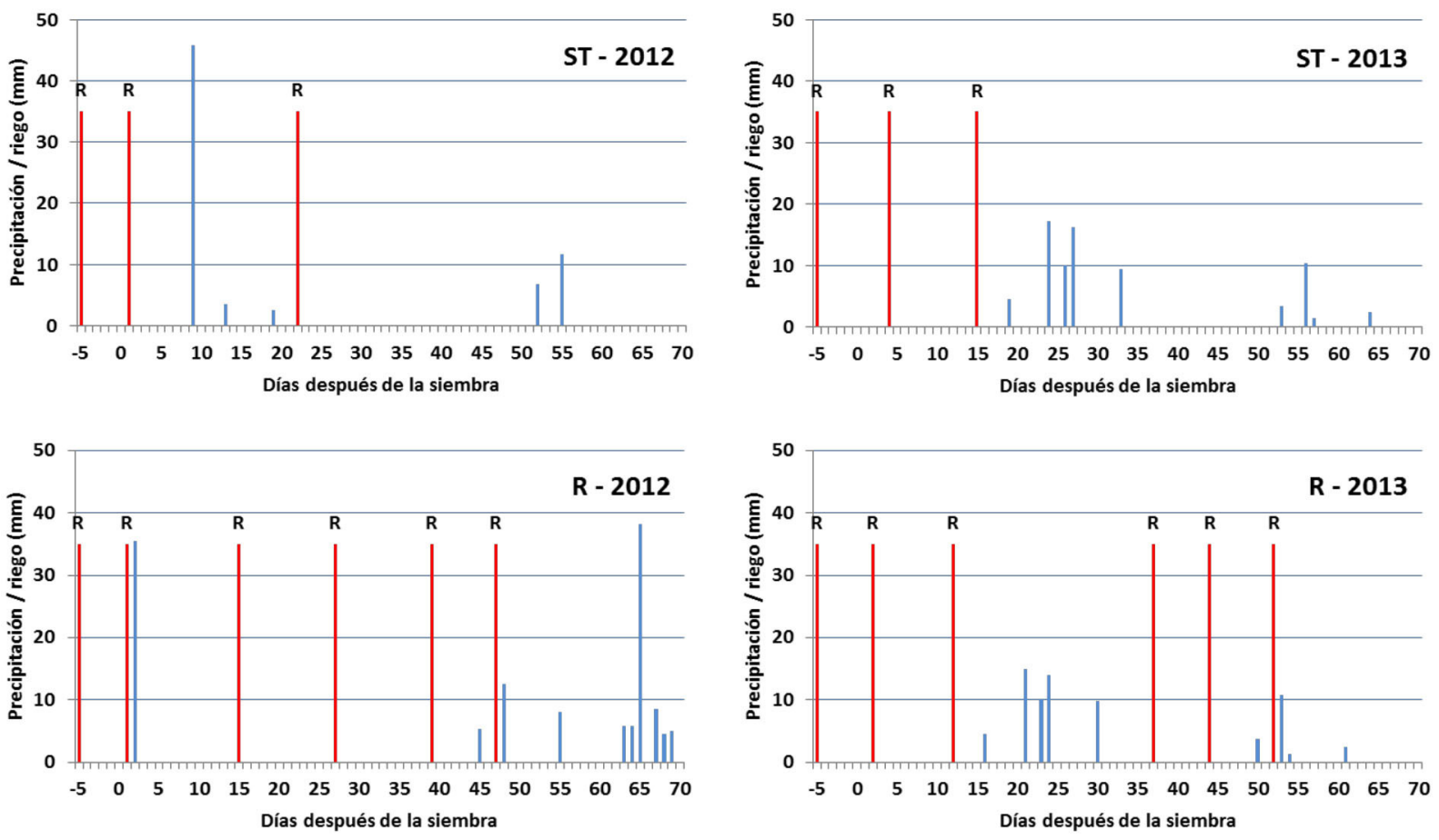

Figura 1. Precipitación y cantidad de agua suministrada mediante riego a dieciséis genotipos de frijol evaluados bajo riego (R) y sequía terminal (ST). Centro Internacional de Agricultura Tropical (CIAT), Palmira, Colombia. 2012-2013.

Figure 1. Rainfall and water supplied through irrigation events to sixteen bean genotypes evaluated under irrigation $(\mathrm{R})$ and terminal drought (ST). Centro Internacional de Agricultura Tropical (CIAT), Palmira, Colombia. 2012-2013.

El análisis estadístico combinado determinó diferencias altamente significativas $(\mathrm{p} \leq 0,01)$ entre ambientes para todas las variables de medición directa, excepto en los días a floración. Igualmente, se tuvieron diferencias significativas $(\mathrm{p} \leq 0,05)$ entre genotipos para todas las variables y una interacción significativa $(\mathrm{p} \leq 0,05)$ genotipo*ambiente, en todos los casos, excepto en la producción de biomasa. Por el contrario, no se obtuvieron diferencias significativas entre los dos años de estudio. Lo anterior, refleja el contraste entre los dos ambientes estudiados y la idoneidad de las condiciones en que se realizaron los ensayos para determinar resistencia a la sequía terminal.

La producción de biomasa de los genotipos evaluados se vio significativamente afectada por el estrés por sequía terminal y se pasó de una media general de $4705 \mathrm{~kg} / \mathrm{ha}$ en condición sin estrés a una de $2586 \mathrm{~kg} / \mathrm{ha}$ en condición de sequía terminal, con una reducción promedio del $47 \%$ (Cuadro 3). Dentro de las líneas evaluadas, las líneas NCB 226, SCR 9, SXB 412, BFS 29 y ALB 74, fueron las que produjeron mayor cantidad de biomasa en condición de sequía terminal. De ellas, NCB 226 y BFS 29 fueron de las líneas con menor porcentaje de reducción de biomasa con respecto al ambiente sin estrés, y de las de mayor rendimiento en sequía terminal. Por el contrario, 


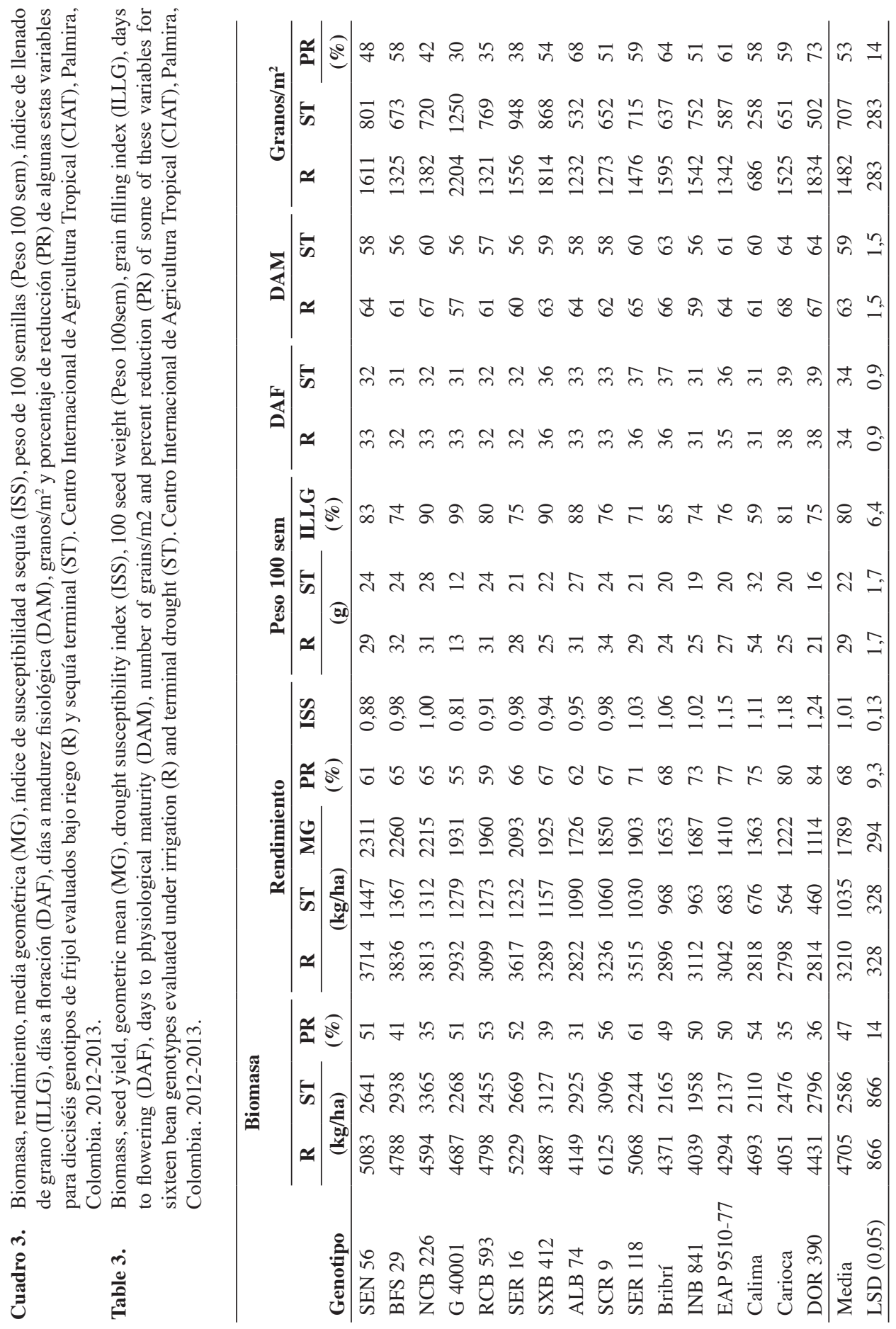


DOR 390 resultó un buen productor de biomasa en estrés, pero con bajo rendimiento. La producción de biomasa bajo estrés se asoció de forma débil y positiva con el rendimiento en esa condición $(r=0,25 ; \mathrm{p} \leq 0,05)$.

El rendimiento de todos los genotipos evaluados en sequía terminal fue significativamente más bajo que su contraparte en la condición sin estrés, y se redujo en promedio un $68 \%$ (Cuadro 3). El rendimiento promedio de los genotipos varió de 2798 a 3836 kg/ha en condición sin estrés y de 460 a $1447 \mathrm{~kg} / \mathrm{ha}$ bajo estrés por sequía terminal, donde se presentaron diferencias altamente significativas entre genotipos. SEN 56 destacó como la línea de mayor rendimiento, seguida por BFS 29, NCB 226, G 40001, RCB 593 y SER 16; materiales que a la vez presentaron las mayores MG ( $>1931 \mathrm{~kg} / \mathrm{ha})$ y menores ISS $(<1,00)$. Tanto la MG $(\mathrm{r}=0,95 ; \mathrm{p} \leq 0,01)$ como el ISS $(\mathrm{r}=-0,87 ; \mathrm{p} \leq 0,01)$ se asociaron de manera fuerte y altamente significativa con el rendimiento en sequía terminal.

El peso de la semilla se redujo como consecuencia del estrés por sequía terminal y esto se reflejó en el índice de llenado de grano (ILLG), que mide cuanto se acercó el peso del grano en condición de estrés al de la condición sin estrés. El ILLG varió de 71 a 99\% y obtuvo un promedio de 80\% (Cuadro 3). Los genotipos que obtuvieron un mayor ILLG fueron G 40001, NCB 226, SXB 412, ALB 74, Bribrí y SEN 56. De ellos, G 40001, SEN 56 y NCB 226 fueron de los más productivos en condición de sequía terminal, y en el caso de G 40001 (frijol tépari), su peso de semilla prácticamente no se vio afectado por este tipo de estrés. Con respecto al número de granos $/ \mathrm{m}^{2}$, el estrés por sequía terminal redujo su promedio desde 1482 a 707 (Cuadro 3). Los genotipos capaces de producir un mayor número de granos por metro cuadrado, como G 40001, SER 16, SXB 412, SEN 56 y RCB 593, fueron de los que obtuvieron un mayor rendimiento en sequía terminal. Esta variable presentó una correlación positiva moderada $(r=-0,43 ; p \leq 0,01)$ con el rendimiento en sequía terminal.

No se presentaron diferencias en la cantidad de días necesarios para alcanzar la floración (DAF) al comparar entre ambientes, solo la variación asociada a los distintos genotipos evaluados (Cuadro 3). A pesar de ello, es importante destacar que este parámetro, tanto en sequía $(\mathrm{r}=-0,33 ; \mathrm{p} \leq 0,01)$ como en riego $(\mathrm{r}=-0,45 ; \mathrm{p} \leq 0,01)$, correlacionó de forma negativa con el rendimiento en sequía terminal. Los genotipos con mayor rendimiento en sequía terminal, fueron de los que llegaron a floración más temprano. Por el contrario, genotipos altamente sensibles a la sequía, como DOR 390, Carioca y EAP 9510-77, fueron de los más tardíos en alcanzar la floración.

El estrés por sequía terminal causó una disminución en la cantidad de días requeridos para completar el ciclo de cultivo. En promedio se pasó de 63 a 59 días para llegar a la madurez fisiológica (Cuadro 3). Dentro de los genotipos con mayor rendimiento en sequía terminal están los que alcanzaron la madurez fisiológica en menor cantidad de días: G 40001, BFS 29, SER 16 y RCB 593. Al respecto, se encontró una correlación negativa y altamente significativa $(\mathrm{r}=-0,52 ; \mathrm{p} \leq 0,01)$, entre los días a madurez fisiológica y el rendimiento en condición de sequía terminal.

El estrés por sequía terminal afectó la capacidad de todos los genotipos para llevar a cabo una partición de asimilados adecuada, medida indirectamente a través de la acumulación de biomasa en vainas y granos, y los índices de IC, ICV e IPV. Para todos los índices se dieron diferencias significativas entre ambientes y entre genotipos (Cuadro 4). La sequía terminal ocasionó que la media general para el IC bajara de $72 \%$ en riego a $49 \%$ en condición de estrés, para el ICV de 79 a $75 \%$ y para el IPV de 82 a 58\%. Los resultados obtenidos en este estudio indicaron que los genotipos con mayor IC, ICV e IPV estuvieron dentro de los genotipos con mayor rendimiento en sequía terminal. A pesar de ello, se presentó una correlación positiva pero débil entre el rendimiento en sequía terminal y el IC $(\mathrm{r}=0,26 ; \mathrm{p} \leq 0,01)$, el ICV $(\mathrm{r}=0,23 ; \mathrm{p} \leq 0,01)$ y IPV $(\mathrm{r}=0,33 ; \mathrm{p} \leq 0,01)$. Dentro de los genotipos evaluados, se destacaron por su capacidad para acumular biomasa en los órganos reproductivos G 40001, SER 16, SER 118 e INB 841, que presentaron los mayores valores de IC, ICV e IPV, seguidos por RCB 593 y SEN 56 con un alto IC e IPV (Cuadro 4).

Los parámetros fisiológicos evaluados presentaron diferencias altamente significativas entre las medias de cada ambiente, excepto para la eficiencia del fotosistema II. Al comparar el ambiente de R con ST, la media general del contenido de clorofila pasó de 41 a 46 unidades $\operatorname{SPAD}\left(\mathrm{LSD}_{0,001}=1,4\right)$, la conductancia estomática disminuyó de 513 a $267 \mathrm{mmol} / \mathrm{m}^{2} / \mathrm{s}\left(\mathrm{LSD}_{0,001}=55\right)$, la depresión de temperatura del dosel bajó de 7,2 a 3,0 ${ }^{\circ} \mathrm{C}\left(\mathrm{LSD}_{0,001}=2,2\right)$ y el índice 
Cuadro 4. Índices de cosecha (IC), de cosecha de vainas (ICV) y de partición a vainas (IPV) para dieciséis genotipos de frijol evaluados bajo riego (R) y sequía terminal (ST). Centro Internacional de Agricultura Tropical (CIAT), Palmira, Colombia. 2012-2013.

Table 4. Harvest index (IC), pod havest index (ICV), and pod partitioning index (IPV), for sixteen bean genotypes evaluated under irrigated (R) and terminal drought (ST) stress conditions. Centro Internacional de Agricultura Tropical (CIAT), Palmira, Colombia. 2012-2013.

\begin{tabular}{|c|c|c|c|c|c|c|}
\hline \multirow[b]{2}{*}{ Identificación } & \multicolumn{2}{|c|}{ IC (\%) } & \multicolumn{2}{|c|}{$\operatorname{ICV}(\%)$} & \multicolumn{2}{|c|}{ IPV (\%) } \\
\hline & $\mathbf{R}$ & ST & $\mathbf{R}$ & ST & $\mathbf{R}$ & ST \\
\hline ALB 74 & 77 & 39 & 78 & 74 & 83 & 53 \\
\hline BFS 29 & 77 & 44 & 80 & 75 & 90 & 58 \\
\hline Bribrí & 77 & 47 & 80 & 76 & 87 & 55 \\
\hline Calima & 59 & 33 & 76 & 70 & 76 & 46 \\
\hline Carioca & 77 & 40 & 78 & 70 & 89 & 56 \\
\hline DOR 390 & 72 & 19 & 76 & 68 & 82 & 29 \\
\hline EAP 9510-77 & 63 & 55 & 77 & 74 & 74 & 57 \\
\hline G 40001 & 53 & 59 & 80 & 78 & 66 & 73 \\
\hline INB 841 & 82 & 58 & 80 & 77 & 82 & 63 \\
\hline NCB 226 & 85 & 50 & 81 & 76 & 83 & 57 \\
\hline RCB 593 & 70 & 66 & 78 & 75 & 85 & 78 \\
\hline SCR 9 & 57 & 46 & 78 & 75 & 73 & 50 \\
\hline SEN 56 & 76 & 58 & 78 & 75 & 83 & 69 \\
\hline SER 16 & 70 & 65 & 81 & 77 & 87 & 62 \\
\hline SER 118 & 69 & 59 & 82 & 80 & 85 & 56 \\
\hline SXB 412 & 79 & 49 & 77 & 73 & 91 & 68 \\
\hline Media general & 72 & 49 & 79 & 75 & 82 & 58 \\
\hline $\operatorname{LSD}(0,05)$ & 21 & 21 & 2 & 2 & 20 & 20 \\
\hline
\end{tabular}

de área foliar de 4,00 a $1,95\left(\operatorname{LSD}_{0,001}=0,43\right)$. Además, la conductancia estomática $(\mathrm{r}=0,30 ; \mathrm{p} \leq 0,01)$, la depresión de temperatura del dosel $(r=0,28 ; \mathrm{p} \leq 0,01)$ y el índice de área foliar $(\mathrm{r}=0,26 ; \mathrm{p} \leq 0,01)$ correlacionaron de forma positiva, pero débil, con el rendimiento en sequía terminal.

La llegada de un período de sequía dentro del ciclo de cultivo es incierta, por lo que, no se puede prevenir. Debido a esta razón, es importante enfocar el mejoramiento del cultivo por resistencia a sequía hacia genotipos que tengan rendimientos altos, tanto en una condición de estrés como cuando no la haya. Bajo este precepto, BFS 29, NCB 226, SEN 56 y SER 16 fueron las mejores líneas (Figura 2), con excelentes rendimientos en ambos ambientes y que podrían representar una solución para las zonas propensas a sufrir sequía terminal. Estos genotipos obtuvieron al menos un 15 y 50\% más de rendimiento en riego y sequía terminal, respectivamente, que el testigo comercial EAP 9510-77. BFS 29, NCB 226 y SEN 56, también superaron en rendimiento en ambas condiciones a otros testigos como DOR 390 y Bribrí. Otros genotipos que mostraron rendimientos por encima de EAP 9510-77 en sequía terminal fueron ALB 74 y RCB 593. 


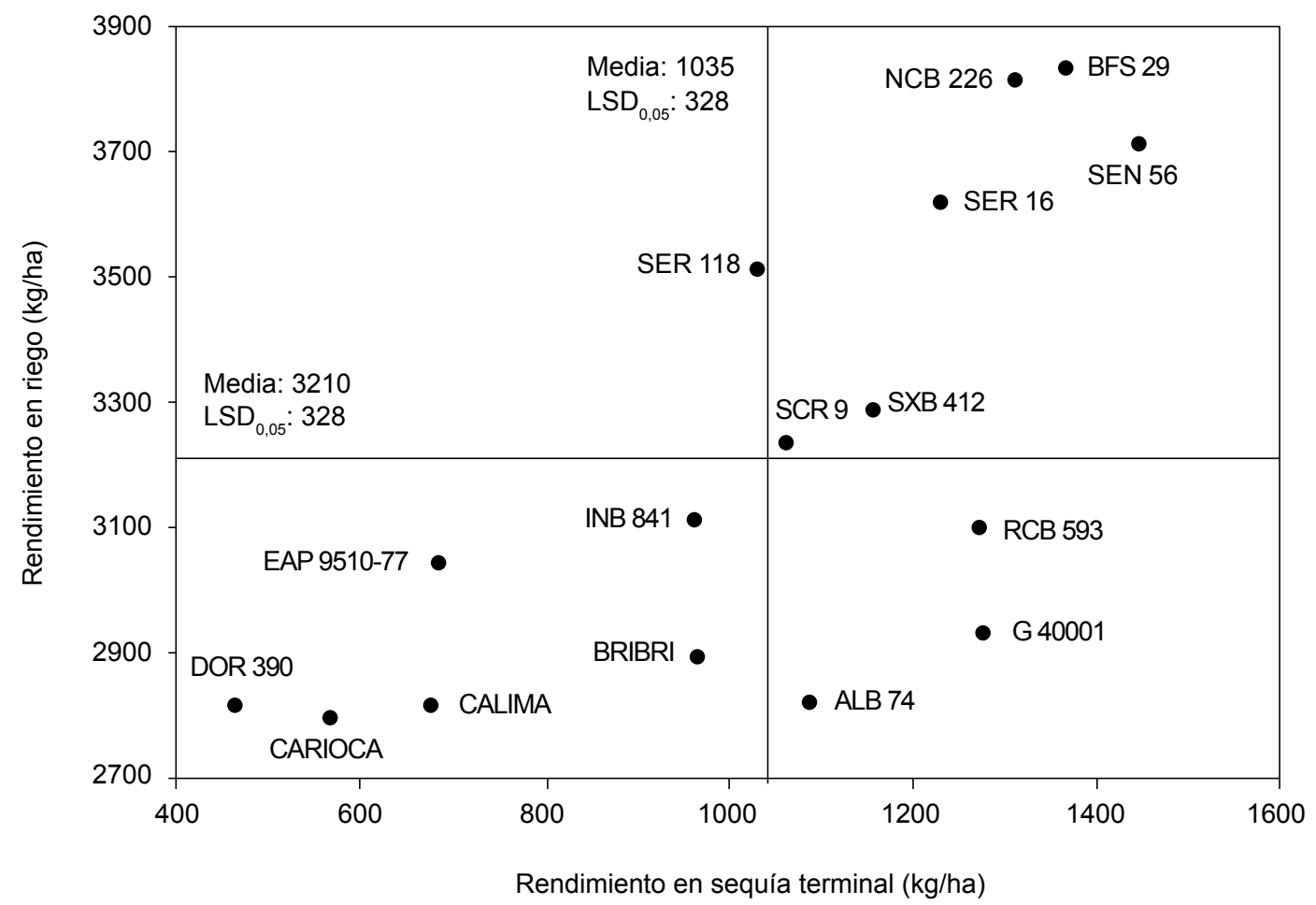

Figura 2. Comparación de germoplasma de frijol de acuerdo con su media combinada de rendimiento en riego y bajo sequía terminal para los años 2012 y 2013. Centro Internacional de Agricultura Tropical (CIAT), Palmira, Colombia.

Figure 2. Comparison of bean germplasm according to its combined yield mean under irrigated and terminal drought stress conditions for years 2012 and 2013. Centro Internacional de Agricultura Tropical (CIAT), Palmira, Colombia.

\section{Discusión}

El índice de intensidad de sequía (IIS), indica el grado de estrés al que fueron sometidos los genotipos y la idoneidad de las condiciones que se tuvieron en este estudio para la identificación de materiales con resistencia a sequía terminal. Tanto en el 2012 como en el 2013 se obtuvieron IIS superiores a 0,50, que se consideran altos y pueden ocasionar reducciones del 20-100\% en la producción de biomasa, el rendimiento y sus distintos parámetros en frijol común (Muñoz-Perea et al., 2007). Los valores de IIS obtenidos fueron similares a los de otros estudios realizados en CIAT, de 0,57 a 0,67 (Terán y Singh, 2002b) y a los de investigaciones llevadas a cabo en otros países con condiciones tropicales, como Puerto Rico, de 0,50 a 0,64 (Porch et al., 2009). De acuerdo con los valores de IIS obtenidos, se tuvieron condiciones óptimas para la identificación de genotipos con mayor resistencia a sequía terminal.

La condición de estrés por sequía terminal indicada por el IIS, causada por la escasa precipitación, alta evapotranspiración y la suspensión del riego antes de la floración, ocasionó la caída de los rendimientos, debido a que, la fase reproductiva es la más sensible a la sequía en el frijol común (Muñoz-Perea et al., 2007). Durante más de la mitad del ciclo de cultivo se presentaron días con alta evapotranspiración; sin embargo, esta condición solo ocasionó un marchitamiento incipiente de las plantas en horas del mediodía e inicios de la tarde, acorde con lo indicado por Porch et al. (2009). 
El contraste encontrado en las dos condiciones estudiadas se reflejó estadísticamente, en concordancia con investigaciones similares (Terán y Singh, 2002b; Muñoz-Perea et al., 2006; Porch et al., 2009). Las diferencias significativas encontradas entre genotipos, así como en la interacción genotipo-ambiente para la mayoría de variables, permitieron discriminar entre genotipos dentro de cada ambiente, ya que existe una respuesta diferencial y varía el orden de los mismos según las condiciones ambientales en que se encuentren. La similitud de condiciones entre los dos años de estudio permitió evaluar la estabilidad de la respuesta de los genotipos en el tiempo.

Las líneas de frijol común más productivas bajo sequía terminal fueron SEN 56, BFS 29, NCB 226, RCB 593 y SER 16, que presentaron altas MG y bajos ISS. Al respecto, Ramírez-Vallejo y Kelly (1998), Frahm et al. (2004) y Porch et al. (2009) consideraron que la MG y el ISS, son de los mejores parámetros para seleccionar genotipos resistentes a sequía, y la asociación fuerte y altamente significativa que presentaron ambas variables con el rendimiento en sequía terminal, confirmó lo indicado por dichos investigadores. Dentro de las líneas más productivas en sequía terminal, SEN 56, NCB 226 y SER 16, ya habían obtenido buenos rendimientos en sequía en ensayos previos llevados a cabo en CIAT (Beebe et al., 2008; 2014). Además de su resistencia a sequía, NCB 226, también ha obtenido buen rendimiento en condiciones de bajo fósforo (Beebe et al., 2008).

Las líneas de frijol común más resistentes obtuvieron rendimientos similares o superiores a G 40001 en sequía terminal, indicativo de su buena adaptación y resistencia a este tipo de estrés. G 40001 es una accesión de P. acutifolius, especie con alto grado de resistencia a sequía y temperatura elevada, debido a caracteres como maduración temprana, excelente capacidad de removilización, enraizamiento fino y profundo, gran conductividad hidráulica, hojas pequeñas para reducir el uso de agua y control estomático (Muñoz et al., 2004; 2006; Micheletto et al., 2007, Beebe et al., 2013; 2014). P. acutifolius se considera una fuente potencial de genes y caracteres valiosos para el mejoramiento del frijol común a sequía y alta temperatrura (Beebe et al., 2013; Porch et al., 2013; Rao et al., 2013), como lo demostró en este estudio, donde presentó alto rendimiento en sequía terminal, la menor reducción en rendimiento con respeto al ambiente sin estrés, mayor cantidad de granos por $\mathrm{m}^{2} \mathrm{y}$ un excelente llenado de grano.

El alto rendimiento en sequía terminal que presentaron las líneas más resistentes, se puede explicar genética y morfológicamente. SER 16 posee dentro de sus progenitores a SEA 15, una de las fuentes más frecuentes de genes Durango, raza de donde proviene la mayor parte de la resistencia a sequía en frijol común (Terán y Singh, 2002a; Beebe et al., 2008; 2013). NCB 226 es derivada de la accesión G 21212 de la sub-raza M2 Mesoamérica, que posee genes que contribuyen a la resistencia a sequía, llenado de grano y fuerza de sumidero (Beebe et al., 2008). BFS 29 posee a NCB 226 y SER 118 dentro de sus progenitores, y SER 118 posee gran resistencia a la sequía, asociada a su gran habilidad para removilizar fotosintatos (Klaedtke et al., 2012). Morfológicamente, SEN 56, NCB 226 y SER 16 se caracterizan por desarrollar un sistema radical bastante profundo y vigoroso en condición de sequía, atributo que les permite extraer una mayor cantidad de agua desde los perfiles inferiores del suelo, y contribuye a conferirles una alta resistencia a este tipo de estrés (Polanía et al., 2009; 2012).

La cantidad de biomasa producida también es uno de los criterios más útiles para la selección de resistencia a sequía (Rosales-Serna et al., 2004). NCB 226 y BFS 29, dos de las líneas con mayor producción de biomasa bajo sequía terminal, fueron de las de mayor rendimiento bajo estrés, por lo que, esta característica es uno de los atributos que les confiere mayor resistencia a sequía terminal. Sin embargo, para lograr buenos rendimientos en sequía terminal un genotipo no solo requiere de producir abundante biomasa, sino debe transformarla en grano, condición que quedó clara en el caso de DOR 390. Este es un genotipo que produce abundante biomasa a mitad de llenado de grano, pero su rendimiento es bajo, ya que no presenta una buena acumulación en los órganos reproductivos, durante estrés por sequía (Beebe et al., 2014).

El peso de la semilla se ve afectado por la sequía terminal, pero también es un carácter muy ligado a cada genotipo, por lo que, la forma correcta de interpretar el efecto del estrés sobre este parámetro es a través de su reducción con respecto al ambiente sin estrés. Esta reducción está implícita en el ILLG, por lo que, este índice puede ayudar a discriminar la respuesta de los genotipos al estrés por sequía. Además del peso de la semilla, la 
sequía terminal causa una fuerte disminución en el número de granos $/ \mathrm{m}^{2}$. Así, las líneas capaces de producir un mayor número de granos $/ \mathrm{m}^{2}$ bajo estrés, como SEN 56 y SER 16, o de llenarlos bien como NCB 226, fueron de las que obtuvieron un mayor rendimiento en sequía terminal. Lo anterior sugiere que, un genotipo resistente a sequía terminal debe producir buena cantidad de granos y ser capaz de llenarlos.

El inicio de la floración no presentó diferencias entre ambientes, debido a que cuando inicia esta etapa, el estrés por sequía terminal aún es muy incipiente. Sin embargo, se presentó una correlación negativa moderada y altamente significativa de este parámetro, tanto en estrés como sin estrés, con el rendimiento en sequía terminal. Esto sugiere que la precocidad en la floración de un genotipo, es un atributo relacionado con una mayor resistencia a sequía terminal. Por otro lado, los genotipos más resistentes alcanzaron la madurez fisiológica en menor cantidad de días. Al respecto, se conoce que una de las respuestas de la planta de frijol común al estrés hídrico es acortar el número de días para llegar a madurez y la etapa de llenado de grano (Ramírez-Vallejo y Kelly, 1998; Terán y Singh, 2002a; 2002b). Además, se considera que la precocidad en la maduración es una característica muy valiosa en la adaptación del frijol común a sequía terminal (White y Singh, 1991a; Rosales et al., 2004; Beebe at al., 2013), ya que permite completar el llenado del grano con una mayor disponibilidad de agua con respecto a genotipos más tardíos. La correlación negativa y altamente significativa entre los días a madurez fisiológica y el rendimiento en condición de sequía terminal, refrendó lo encontrado por Ramírez-Vallejo y Kelly (1998) y Terán y Singh (2002a) en estudios similares.

La capacidad de los genotipos resistentes para producir mayor cantidad de biomasa y removilizar fotosintatos desde los órganos vegetativos a las vainas y luego a las semillas, es crucial para minimizar los efectos adversos del estrés por sequía y lograr buenos rendimientos bajo esta condición de estrés; además de, compensar la penalización en rendimiento por precocidad en la maduración, estimada en $74 \mathrm{~kg} / \mathrm{ha}$ por día (White y Singh, 1991b; MuñozPerea et al., 2007; Klaedtke et al., 2012, Rao et al., 2013). Al respecto, el IC, ICV y el IPV han sido parámetros útiles para identificar genotipos resistentes a la sequía (Assefa et al., 2013; Beebe et al., 2013; Polanía et al., 2016). El IC expresa cuánto de la biomasa total de la parte aérea de la planta se acumuló en el grano, el IPV cuánto de esa biomasa total se acumuló en las vainas y el ICV indica cuánto de la biomasa de las vainas corresponde al grano. En esta investigación, se destacaron como movilizadores G 40001, SER 16, SEN 56, RCB 593, SER 118 e INB 841, y los primeros cuatro obtuvieron altos rendimientos en sequía terminal (>1200 kg/ha)

SER 118 e INB 841 obtuvieron un rendimiento intermedio en sequía terminal, pero podrían servir como padres para mejora genética a este tipo de estrés, y tratar de heredar a la progenie su mayor capacidad para acumular biomasa en los órganos reproductivos. SER 118, que se caracteriza por ser un buen padre y rendir bien en bajo fósforo (Beebe et al., 2008; 2014), fue el genotipo con mayor ICV. Se ha encontrado que el ICV tiene mayor heredabilidad que el rendimiento en sequía y la selección basada en este carácter podría contribuir más a la obtención de ganancias en productividad bajo sequía, que la selección por rendimiento per se (Assefa et al., 2013). Por su parte, INB 841 procede de una población generada mediante cruzamientos interespecíficos con P. acutifolius, y fue seleccionada por su rápida elongación de vainas en sequía. Representa la posibilidad de introgresar los genes valiosos que posee frijol tépari en frijol común, para el mejoramiento de la resistencia al estrés por sequía y alta temperatura.

Al medir el contenido de clorofila en unidades SPAD se detectó un aumento en las hojas de las plantas en sequía terminal, comportamiento similar al observado en otras investigaciones en frijol común (Rosales-Serna et al., 2004; Polanía et al., 2009). A pesar de que, el estrés por sequía produce una reducción en el contenido de clorofila (Rosales et al., 2004), por la metodología de medición y un efecto de concentración, al presentarse hojas más pequeñas y menos hidratadas, aumenta el número de células por unidad de área y da el resultado obtenido. La conductancia estomática, la diferencia de temperatura entre el dosel y el ambiente, y el índice de área foliar se redujeron. Al reducirse la transpiración durante el estrés por sequía como medida para conservar agua o por la limitante de agua en el suelo, la planta reduce su conductancia estomática y pierde capacidad de enfriarse, por 
lo que, su diferencial de temperatura con respecto al ambiente decae. Por otro lado, al reducirse la cantidad de biomasa y el área foliar por efecto de la sequía (Rosales-Serna et al., 2004; Núñez et al., 2005; Beebe et al., 2013), el índice de área foliar se ve reducido. A pesar de que los efectos de la sequía en la fisiología de la planta son claros, al no presentarse diferencias estadísticas entre genotipos, las variables medidas no fueron útiles para explicar las diferencias observadas en el rendimiento de los genotipos evaluados.

En la actualidad, el mejoramiento genético a estrés abiótico busca genotipos capaces de rendir bien en un ambiente con estrés como en una condición sin estrés. En esta investigación y bajo este enfoque, se destacaron BFS 29, NCB 226, SEN 56 y SER 16, que superaron en ambos ambientes a EAP 9510-77, testigo comercial para Centroamérica (Rosas et al., 2004b). Además, BFS 29, NCB 226 y SEN 56 también superaron en resistencia a sequía y en rendimiento en condiciones sin estrés, a DOR 390 y Bribrí, cultivares de uso comercial en Centroamérica (Rosas et al., 2003; 2004a; Hernández y Elizondo, 2006). Esto indica el avance en la mejora genética para resistencia a estrés por sequía terminal y el potencial de las líneas identificadas, ya sea como fuentes de resistencia para programas de mejoramiento genético o para ser evaluadas in situ como materiales comerciales, ya que cuentan con características de alto valor como su arquitectura erecta, color y tono del grano.

Las líneas ALB 74 y RCB 593, con rendimiento y adaptación superior a EAP 9510-77 en sequía terminal, y que poseen un color rojo brillante comercial, podrían ser utilizadas también como fuentes de resistencia. Además, estos genotipos presentan otra característica muy valiosa para Centroamérica y el sur de México, como lo es su resistencia al virus del mosaico amarillo dorado del frijol (BGYMV); según evaluaciones llevadas a cabo por CIAT del 2010 al 2014 en El Salvador, bajo una alta presión de inóculo natural y cuyo vector (Bemisia tabaci Genn.) se vio favorecido por condiciones más secas y calientes (Gálvez y Morales, 1994; Cuéllar y Morales, 2006).

\section{Conclusiones}

Las líneas de frijol común SEN 56, BFS 29, NCB 226 y SER 16 mostraron alto rendimiento tanto en condición sin estrés (riego) como en sequía terminal, por lo que, podrían constituir una alternativa para las zonas propensas a sufrir problemas por sequía. Además de poseer características de alto valor comercial como arquitectura erecta, color y tono del grano, superaron en rendimiento a EAP 9510-77, testigo comercial para Centroamérica, en los dos ambientes evaluados.

RCB 593, ALB 74 y G 40001 (frijol tépari) mostraron altos rendimientos en sequía terminal y aceptables en riego, por lo que, junto con SER 118 e INB 841, que poseen características valiosas para la resistencia a este tipo de estrés, podrían ser considerados como padres en programas de mejoramiento.

La capacidad de los genotipos para producir biomasa y acumularla en los órganos reproductivos, acelerar la madurez y producir mayor cantidad de granos $/ \mathrm{m}^{2}$ bajo estrés, fueron atributos relacionados con una mayor resistencia a la sequía terminal.

\section{Agradecimientos}

Los autores de este trabajo agradecen a la Universidad de Costa Rica y al Centro Internacional de Agricultura Tropical (CIAT), entidades que financiaron los estudios doctorales del primer autor en la Universidad Nacional de Colombia Sede Palmira. A la Fundación Bill y Melinda Gates (BMGF) y al programa de investigación del CGIAR sobre leguminosas de grano, por el apoyo financiero de esta investigación. También se agradece a los ingenieros Cesar Cajiao, Miguel Grajales y Juan Cuasquer, por su ayuda profesional en este trabajo. 


\section{Literatura citada}

Assefa, T., S.E. Beebe, I.M. Rao, J.B. Cuasquer, M.C. Duque, M. Rivera, A. Battisti, and M. Lucchin. 2013. Pod harvest index as a selection criterion to improve drought resistance in white pea bean. Field Crops Res. 148:24-33. doi:10.1016/j. fcr.2013.04.008

Bartlett, M.S. 1947. The use of transformations. Biometrics 3:39-52.

Beebe, S.E. 2012. Common bean breeding in the tropics. Plant Breed. Rev. 36:357-426. doi:10.1002/9781118358566.ch5

Beebe, S.E., I.M. Rao, M.W. Blair, and J.A. Acosta. 2013. Phenotyping common beans for adaptation to drought. Front. Physiol. 4:35. doi:10.3389/fphys.2013.00035

Beebe, S., I. Rao, M.W. Blair, and L. Butare. 2009. Breeding for abiotic stress tolerance in common bean: present and future challenges. Paper presented at: $14^{\text {th }}$ Australian Plant Breeding and $11^{\text {th }}$ Society for Advancement of Breeding Research in Asia and Oceania (SABRAO), Brisbane, AUS. 10-14 Aug.

Beebe, S.E., I.M. Rao, C. Cajiao, and M. Grajales. 2008. Selection for drought resistance in common bean also improves yield in phosphorus limited and favorable environments. Crop Sci. 48:582-592. doi:10.2135/cropsci2007.07.0404

Beebe, S.E., I.M. Rao, M.J. Devi, and J. Polanía. 2014. Common beans, biodiversity, and multiple stresses: Challenges of drought resistance in tropical soils. Crop Pasture Sci. 65:667-675. doi:10.1071/CP13303

Beebe, S., J. Ramírez, A. Jarvis, I.M. Rao, G. Mosquera, J.M. Bueno, and M.W. Blair. 2011. Genetic improvement of common beans and the challenges of climate change. In: S.S. Yadav et al., editors, Crop adaptation to climate change. WileyBlackwell, Oxford, GBR. p. 356-369.

Blair, M.W., W. Pantoja, and L.C. Carmenza-Muñoz. 2012. First use of microsatellite markers in a large collection of cultivated and wild accessions of tepary bean (Phaseolus acutifolius A. Gray). Theor. Appl. Genet. 125:1137-1147. doi: 10.1007/ s00122-012-1900-0

Broughton, W.J., G. Hernández, M. Blair, S. Beebe, P. Gepts, and J. Vanderleyden. 2003. Beans (Phaseolus spp.) - model food legumes. Plant Soil 252:55-128. doi: 10.1023/A:1024146710611

Castellanos, J.Z., J.J. Peña-Cabriales, and J.A. Acosta-Gallegos. 1996. 15N-determined dinitrogen fixation capacity of common bean (Phaseolus vulgaris) cultivars under water stress. J. Agr. Sci. 126:327-333. doi:10.1017/S0021859600074888

Cuéllar, M.E., y F.J. Morales. 2006. La mosca blanca Bemisia tabaci (Gennadius) como plaga y vectora de virus en fríjol común (Phaseolus vulgaris L.). Rev. Colomb. Entomol. 32(1):1-9.

dos-Santos, M.G., R.V. Ribeiro, R.F. de-Oliveira, and C. Pimentel. 2004. Gas exchange and yield response to foliar phosphorus application in Phaseolus vulgaris L. under drought. Braz. J. Plant Physiol. 16:171-179. doi:10.1590/S167704202004000300007

Fernández, W., y P. Ramírez. 1991. El Niño, la Oscilación del Sur y sus efectos en Costa Rica: una revisión. Tecnol. Marcha 11(1):3-10.

Fischer, R.A., and R. Maurer. 1978. Drought resistance in spring wheat cultivars. I. Grain yield responses. Aust. J. Agric. Res. 29:897-912. doi:10.1071/AR9780897

Foster, E.F., A. Pajarito, and J. Acosta-Gallegos. 1995. Moisture stress impact on N partitioning, N remobilization and N use efficiency in beans (Phaseolus vulgaris). J. Agr. Sci. 124:27-37. doi:10.1017/S0021859600071215

Frahm, M.A., J.C. Rosas, N. Mayek-Pérez, E. López-Salinas, J.A. Acosta-Gallegos, and J.D. Kelly. 2004. Breeding beans for resistance to terminal drought in the lowland tropics. Euphytica 136:223-232. doi:10.1023/B:EUPH.0000030678.12073.a9 
Freytag, G.F., and D.G. Debouck. 2002. Taxonomy, distribution and ecology of the genus Phaseolus (LeguminosaePapilionoideae) in North America, Mexico and Central America. Sida Botanical Miscellany, TX, USA.

Gálvez, G.E., y F.J. Morales. 1994. Virus transmitidos por la mosca blanca. En: M. Pastor-Corrales, y H.F. Schwartz, editores, Problemas de producción de frijol en los trópicos. $2^{\text {da }}$ ed. CIAT, Cali, COL. p. 435-472.

Graham, P.H., and P. Rinalli. 1997. Common bean (Phaseolus vulgaris L.). Field Crops Res. 53:131-146. doi:10.1016/S03784290(97)00112-3

Hernández, J.C., R. Araya, y A. Morales. 2001. Bribrí, nueva variedad de frijol rojo pequeño para Costa Rica. Agron. Mesoam. 12(1):15-23.

Hernández, J.C., y F.I. Elizondo. 2006. Estudio sobre la adopción de variedades mejoradas de frijol en las principales zonas productoras de frijol de la región Brunca de Costa Rica. Agron. Mesoam. 17:357-367. doi:10.15517/am.v17i3.5171

Klaedtke, S.M., C. Cajiao, M. Grajales, J. Polanía, G. Borrero, A. Guerrero, M. Rivera, I. Rao, S.E. Beebe, and J. Léon. 2012. Photosynthate remobilization capacity from drought-adapted common bean (Phaseolus vulgaris L.) lines can improve yield potential of interspecific populations within the secondary gene pool. J. Plant Breed. Crop Sci. 4(4):49-61. doi: $10.5897 / \mathrm{JPBCS} 11.087$

McClean, P.E., J. Burridge, S. Beebe, I.M. Rao, and T.G. Porch. 2011. Crop improvement in the era of climate change: an integrated, multi-disciplinary approach for common bean (Phaseolus vulgaris). Funct. Plant Biol. 38:927-933. doi: 10.1071/FP11102.

Micheletto, S., L. Rodríguez-Uribe, R. Hernández, R.D. Richins, J. Curry, and M.A. O’Connell. 2007. Comparative transcript profiling in roots of Phaseolus acutifolius and P. vulgaris under water deficit stress. Plant Sci. 173:510-520. doi:10.1016/j. plantsci.2007.08.003

Muñoz,L.C., M.W. Blair, M.C. Duque, W. J. Thome, and W. Roca. 2004. Introgression in common bean x tepary bean interspecific congruity-backcross lines as measured by AFLP markers. Crop Sci. 44:637-645. doi:10.2135/cropsci2004.0637

Muñoz, L.C., MC. Duque, D.G. Debouck, and M.W. Blair. 2006. Taxonomy of tepary bean and wild relatives as determined by amplified fragment length polymorphism (AFLP) markers. Crop Sci. 46:1744-1754. doi:10.2135/cropsci2005-12-1754

Muñoz-Perea, C.G., R.G. Allen, D.T. Westermann, J.L. Wright, and S.P. Singh. 2007. Water use efficiency among dry bean landraces and cultivars in drought-stressed and non-stressed environments. Euphytica 155:393-402. doi:10.1007/s 10681006-9340-z

Muñoz-Perea, C.G., H. Terán, R.G. Allen, J.L. Wright, D.T. Westermann, and S.P. Singh. 2006. Selection for drought resistance in dry bean landraces and cultivars. Crop Sci. 46:2111-2120. doi:10.2135/cropsci2006.01.0029

Nuñez-Barrios, A., G. Hoogenboom, and D.S. Nesmith. 2005. Drought stress and the distribution of vegetative and reproductive traits of a bean cultivar. Sci. Agric. (Braz.) 62:18-22. doi:10.1590/S0103-90162005000100004

Omae, H., A. Kumar, and M. Shono. 2012. Adaptation to high temperature and water deficit in the common bean (Phaseolus vulgaris L.) during the reproductive period. J. Bot. 2012: Article ID 803413 doi:10.1155/2012/803413

Passioura, J.B. 2002. Soil conditions and plant growth. Plant Cell Environ. 25:311-318. doi: 10.1046/j.0016-8025.2001.00802.x

Polanía, J.A., I.M. Rao, S. Beebe, y R. García. 2009. Desarrollo y distribución de raíces bajo estrés por sequía en frijol común (Phaseolus vulgaris L.) en un sistema de tubos con suelo. Agron. Colomb. 27:25-32.

Polanía, J., I.M. Rao, C. Cajiao, M. Rivera, B. Raatz, and S. Beebe. 2016. Physiological traits associated with drought resistance in Andean and Mesoamerican genotypes of common bean (Phaseolus vulgaris L.). Euphytica 210:17-29. doi: 10.1007/ s10681-016-1691-5 
Polanía, J.A., I.M. Rao, S. Mejía, S.E. Beebe, y C. Cajiao. 2012. Características morfo-fisiológicas de frijol común (Phaseolus vulgaris L.) relacionadas con la adaptación a sequía. Acta Agron. 61:197-206.

Porch, T.G., J.S. Beaver, D.G. Debouck, S.A. Jackson, J.D. Kelly, and H. Dempewolf. 2013. Use of wild relatives and closely related species to adapt common bean to climate change. Agronomy 3:433-461. doi:10.3390/agronomy3020433

Porch, T.G., V.H. Ramírez, D. Santana, and E.W. Harmsen. 2009. Evaluation of common bean for drought tolerance in Juana Diaz, Puerto Rico. J. Agron. Crop Sci. 195:328-334. doi:10.1111/j.1439-037X.2009.00375.x.

Ramírez-Vallejo, P., and J.D. Kelly. 1998. Traits related to drought resistance in common bean. Euphytica 99:127-136. doi:10.1023/A:1018353200015

Rao, I., S. Beebe, J. Polanía, J. Ricaurte, C. Cajiao, R. García, and M. Rivera. 2013. Can tepary bean be a model for improvement of drought resistance in common bean? Afr. Crop Sci. J. 21:265-281.

Rogers, J.C. 1988. Precipitation variability over the Caribbean and tropical Americas associated with the Southern Oscillation. J. Climate 1:172-182.

Rosales-Serna, R., J. Kohashi-Shibata, J.A. Acosta-Gallegos, C. Trejo-López, J. Ortiz-Cereceres, and J.D. Kelly. 2004. Biomass distribution, maturity acceleration and yield in drought-stressed common bean cultivars. Field Crops Res. 85:203-211. doi:10.1016/S0378-4290(03)00161-8

Rosas, J.C., J.S. Beaver, S. Beebe, y A. Viana. 2004a. Nomenclatura de variedades de frijol común liberadas en Centro América y El Caribe. Agron. Mesoam. 15:221-224. doi:10.15517/am.v15i2.11917

Rosas, J.C., J.S. Beaver, D. Escoto, C.A. Pérez, A. Llano, J.C. Hernández, and R. Araya. 2004b. Registration of 'Amadeus 77' small red common bean. Crop Sci. 44:1867-1868. doi:10.2135/cropsci2004.1867

Rosas, J.C., J.C. Hernández, and R. Araya. 2003. Registration of 'Bribri' small red bean (race Mesoamerica). Crop Sci. 43:430431. doi:10.2135/cropsci2003.430a

Singh, S.P. 1995. Selection for water-stress tolerance in interracial populations of common bean. Crop Sci. 35:118-124. doi:10.2135/cropsci1995.0011183X003500010022x

Singh, S.P., P. Gepts, and D.G. Debouck. 1991. Races of common bean (Phaseolus vulgaris, Fabaceae). Econ. Bot. 45:379-396. doi:10.1007/BF02887079

Terán, H., and S.P. Singh. 2002a. Comparison of sources and lines selected for drought resistance in common bean. Crop Sci. 42:64-70. doi:10.2135/cropsci2002.0064

Terán, H., and S.P. Singh. 2002b. Selection for drought resistance in early generations of common bean populations. Can. J. Plant Sci. 82:491-497. doi:10.4141/P01-134

Voysest, O. 2000. Mejoramiento genético del frijol (Phaseolus vulgaris L.): legado de variedades de América Latina. CIAT, Cali, COL.

White, J.W, and S.P. Singh. 1991a. Breeding for adaptation to drought. In: A. Van Schoonhoven, and O. Voysest, editors, Common beans. Research for crop improvement. CIAT, Cali, COL, and CAB International, Wallingford, GBR. p. 501560 .

White, J.W, and S.P. Singh. 1991b. Sources and inheritance of earliness in tropically adapted indeterminated common bean. Euphytica 55:15-19. doi:10.1007/BF00022554

Wortmann, C.S., R.A. Kirkby, C.A. Eledu, and D.J. Allan. 1998. Atlas of common bean (Phaseolus vulgaris L.) production in Africa. CIAT, Cali, COL. 